\title{
Efeito da adubação fosfatada sobre o crescimento e teor de macronutrientes de mudas de pinhão manso ${ }^{1}$
}

\author{
Phosphorus fertilization on growth and contents of macronutrients in Jatropha curcas \\ seedlings
}

\author{
Rosiane de Lourdes Silva de Lima ${ }^{2 *}$, Liv Soares Severino ${ }^{3}$, Hans Raj Gheyi ${ }^{4}$, Valdinei Sofiatti ${ }^{5}$ e Nair Helena \\ Castro Arriel $^{5}$
}

\begin{abstract}
Resumo - A adição de fósforo na composição do substrato para produção de mudas ajuda as raízes e as plântulas a crescerem mais rapidamente, aumenta a resistência aos estresses ambientais e doenças e melhora ainda a eficiência no uso de nutrientes e da água em várias espécies vegetais. Objetivou-se, com este estudo, avaliar o efeito da adição de superfosfato simples no substrato sobre o crescimento e teor foliar de macronutrientes de mudas de pinhão manso (Jatropha curcas). O substrato contendo material de solo e composto de lixo recebeu as doses de $0 ; 2,5 ; 5,0 ; 7,5 ; 10$ e $12,5 \mathrm{~kg} \mathrm{~m}^{-3}$ de superfosfato simples. As mudas foram avaliadas 30 dias após o plantio. $\mathrm{O}$ crescimento máximo das plantas de pinhão manso foi observado com a adição de superfosfato simples ao substrato em doses estimadas na faixa de 5 a $8 \mathrm{~kg} \mathrm{~m}^{-3}$ de substrato. $\mathrm{O}$ fertilizante fosfatado favoreceu o crescimento principalmente de raízes e área foliar e propiciou aumento do teor de todos os macronutrientes no tecido vegetal, exceto o cálcio.
\end{abstract}

Palavras-chave - Adubação fosfatada. Nutrição de plantas. Pinhão-manso.

\begin{abstract}
The addition of phosphorous to the substrate for the production of seedlings promotes faster growth of both root and shoots, increases tolerance to environmental stress and diseases, and even improves the efficiency of nutrient and water use in several plant species. This experiment aimed to study the effect of the addition of simple superphosphate to the substrate on the growth and macronutrient levels in the contents of seedlings of Jatropha curcas. A substrate containing soil and urban-waste compost was modified by the addition of simple superphosphate in $0 ; 2.5 ; 5.0 ; 7.5 ; 10.0$ and $12.5 \mathrm{~kg} \mathrm{~m}^{-3}$ amounts. The seedlings were evaluated 30 days after planting. Maximum growth of the Jatropha plants was observed for the simple superphosphate added in estimated amounts in the range of 5 to $8 \mathrm{~kg} \mathrm{~m}^{-3}$. The phosphorus fertilization especially favored the growth of leaf-area and roots, and promoted increase in contents of all macronutrient except calcium.
\end{abstract}

Key words - Phosphate fertilizer. Plant nutrition. Jatropha.

\footnotetext{
* Autor para correspondência

${ }^{1}$ Recebido para publicação em 25/03/2010; aprovado em 16/05/2011

Trabalho financiado pela FAPESQ/PB/CNPq

${ }^{2}$ Pesquisadora DCR pela Fapesq/PB/CNPq, Rua Osvaldo Cruz, 1143, Centenário, Campina Grande-PB, Brasil, 58.107-720, limarosiane@yahoo.com.br ${ }^{3}$ Doutorando em Agronomia pela Texas Tech University, Lubbock, TX, USA. Rua Osvaldo Cruz, 1143, Centenário, Campina Grande-PB, Brasil,

58.107-720,liv@cnpa.embrapa.br

${ }^{4}$ Núcleo de Engenharia de Água e Solo - UFRB, Cruz das Almas-BA, Brasil, 44,380-000, hans@pq.cnpq.br

${ }_{5}^{5}$ Pesquisadores da Embrapa Algodão, Rua Osvaldo Cruz, 1143, Centenário, Campina Grande-PB, Brasil, 58.107-720, vsofiatti@cnpa.embrapa.br, nair@cnpa.embrapa.br
} 


\section{Introdução}

A composição do substrato é um fator importante para a obtenção de mudas de boa qualidade. Esterco de animais, torta de mamona, casca de amendoim e mucilagem de sisal em mistura com solo em proporções iguais $(\mathrm{v} / \mathrm{v})$, enriquecidos ou não com fertilizante mineral, podem propiciar condições adequadas, tanto no aspecto físico como no nutricional, para a obtenção de mudas com alto padrão de qualidade (SEVERINO; LIMA; BELTRÃO, 2006).

Dentre osnutrientesnecessários ao desenvolvimento da muda, o P é o que requer maior atenção devido ao baixo teor nos solos das regiões tropicais (PRADO; VALE; ROMUALDO, 2005) e a alta demanda em mudas de plantas perenes em sua fase inicial de crescimento (NOVAIS; SMYTH, 1999).

O fósforo está presente em baixas concentrações no solo nas formas aniônicas da dissociação do ácido fosfórico $\left(\mathrm{H}_{3} \mathrm{PO}_{4}\right)$, principalmente como $\mathrm{H}_{2} \mathrm{PO}_{4}^{-}$(fosfato) e $\mathrm{HPO}_{4}^{2-}$ (fosfito) na faixa de variação do $\mathrm{pH}$ dos solos agrícolas (ADAMI; HEBLING, 2005).

O uso de P na formulação do substrato em mistura com material orgânico é uma excelente estratégia para a obtenção de mudas mais vigorosas, pois ajudam na formação do sistema radicular (CRUSCIOL et al., 2005; SANT'ANA et al., 2003; SILVA; DELATORRE, 2009), aumentando a tolerância das plantas aos fatores bióticos e abióticos tais como estresse hídrico (LEÃO, 2006; SANTOS et al., 2004) e doenças (YAMADA, 2002). De acordo com Lacerda et al. (2009) a aplicação de $12 \mathrm{~g} \mathrm{dm}^{-3}$ de superfosfato simples ao substrato contendo $68 \%$ de terra vegetal e $32 \%$ de esterco bovino foi eficiente para a produção de mudas de goiabeira cultivar "Paluma". Para a produção de mudas de Eugenia uvalha em sacos de polietileno, Souza et al. (2009) recomendam a aplicação de $1,30 \mathrm{~kg} \mathrm{~m}^{-3}$ de $\mathrm{P}_{2} \mathrm{O}_{5}$ ao substrato composto por mistura de terra, esterco bovino e areia na proporção de 3:2:1. Já para a cultura do mamoeiro (Carica papaya), Mendonça et al. (2006) recomendam o uso de superfosfato simples na proporção de $10 \mathrm{~kg} \mathrm{~m}^{-3} \mathrm{de}$ substrato, em mistura com $40 \%$ de composto orgânico, para a produção de mudas em sacos plásticos medindo 10 x $20 \mathrm{~cm}$. Para a produção de mudas de pitangueira, em sacos medindo $10 \times 20 \mathrm{~cm}$, Abreu et al. (2005) recomendam o uso de $\mathrm{P}$ na proporção de $6 \mathrm{~kg} \mathrm{~m}^{-3}$ de substrato, aplicado na forma de superfosfato simples, independente da composição do substrato.

Para a produção de mudas de pinhão manso, Carvalho (2008) recomenda o uso de $600 \mathrm{mg} \mathrm{kg}^{-1} \mathrm{de} P$ na forma de superfosfato triplo com colonização micorrízica, enquanto Garcia et al. (2009) recomendam a aplicação de $400 \mathrm{mg} \mathrm{kg}^{-1}$ de $\mathrm{P}$ na forma de superfosfato triplo independente da presença ou ausência de colonização micorízica.

Segundo Vichiato (1996), o fósforo requerido para o ótimo crescimento das plantas varia conforme a espécie ou órgão analisado, variando de 0,1 a $0,5 \%$ da matéria seca. Além de ajudar as raízes e as plântulas a se desenvolverem mais rapidamente, o fósforo aumenta a resistência ao frio, melhora a eficiência no uso da água, favorece a resistência às doenças em algumas plantas (POZZA et al., 2002) e aumenta a absorção de nutrientes, especialmente, do nitrogênio (NOVAIS; SMYTH, 1999). $\mathrm{O}$ uso do superfosfato simples tem tido preferência no fornecimento de fósforo às plantas porque, além do fósforo, contem cálcio e enxofre em sua composição química (CARMELLO, 1995).

Objetivou-se, com este trabalho, avaliar o efeito da adição de superfosfato simples à composição do substrato sobre o crescimento e o teor de macronutrientes na parte aérea de mudas de pinhão manso.

\section{Material e métodos}

O experimento foi conduzido em casa de vegetação da EMBRAPA Algodão, em Campina Grande$\mathrm{PB}$, no período de novembro a dezembro de 2006. Os tratamentos constituíram-se de 6 doses de superfosfato simples $\left(0 ; 2,5 ; 5,0 ; 7,5 ; 10\right.$ e $\left.12,5 \mathrm{~kg} \mathrm{~m}^{-3}\right)$ misturado ao substrato em delineamento inteiramente casualizado com 6 repetições. Utilizou-se como fonte de P o superfosfato simples. A formulação do substrato e a aplicação do fertilizante fosfatado foram realizadas uma semana antes do semeio, misturando-se (v/v) 90\% de material de solo, $10 \%$ de composto de lixo orgânico $(0,92 \%$ de N; $3,29 \%$ de $\mathrm{P}_{2} \mathrm{O}_{5} ; 0,12 \%$ de $\mathrm{K}_{2} \mathrm{O} ; 0,63 \%$ de $\mathrm{CaO} ; 0,36 \%$ de $\mathrm{MgO}$; $0,32 \%$ de $\mathrm{S}$ e $8,98 \%$ de matéria orgânica) e a dose de superfosfato simples $\left(20 \%\right.$ de $\mathrm{P}_{2} \mathrm{O}_{5}, 25 \%$ de $\mathrm{CaO}$ e $12 \%$ de S). A mistura foi homogeneizada e acondicionada em tubetes cônicos com volume de $288 \mathrm{~cm}^{3}$.

Após o acondicionamento dos tubetes na casa de vegetação, o substrato foi umedecido até atingir a capacidade de campo. Após uma semana de incubação, sementes de pinhão manso, procedentes da área experimental de Quixeramobim, CE, foram semeadas. As parcelas foram constituídas por um tubete contendo uma planta, sendo suspensos em uma grade de tela com armações de ferro. As mudas foram irrigadas com água de abastecimento duas vezes por dia, em quantidade suficiente para drenar uma parte.

Aos 30 dias após a semeadura (DAS), mediu-se a altura das plantas, a área foliar, e a massa seca da parte aérea e das raízes. A área foliar foi estimada a partir da 
largura de cada folha, conforme método proposto por Severino, Vale e Beltrão (2007) para o pinhão manso.

Para a avaliação do estádio nutricional das plântulas, a parte aérea das mudas foi separada das raízes, lavada e acondicionada em sacos de papel perfurados, postos em estufa de circulação de ar forçada a $65^{\circ} \mathrm{C}$, até atingir peso constante. Posteriormente, o material vegetal foi moído em moinho tipo Willey e submetidas à digestão sulfúrica para a determinação dos teores de $\mathrm{N}$ e digestão nítrico-perclórica para quantificar os teores de $\mathrm{P}, \mathrm{K}, \mathrm{Ca}$, $\mathrm{Mg}$ e $\mathrm{S}$ na parte aérea das mudas, segundo metodologia proposta por Le Poidevin e Robinson (1964).

Os dados foram analisados por regressão polinomial, testando-se os modelos linear e quadrático com o nível de significância de $5 \%$ pelo Teste F. Três unidades experimentais foram excluídas da análise por morte das plantas (uma no tratamento de $5 \mathrm{~kg} \mathrm{~m}^{-3}$ e duas no tratamento de $\left.10 \mathrm{~kg} \mathrm{~m}^{-3}\right)$. Os coeficientes da equação foram testados no nível de significância de 5\%. Nos casos em que o coeficiente quadrático não foi significativo, os dados foram analisados pelo modelo linear. Os resultados foram apresentados em gráficos com a média dos valores de cada dose de superfosfato simples, seus respectivos desvios-padrão e a curva de regressão.

\section{Resultados e discussão}

Nas Tabelas 1 e 2 são apresentados os resumos da análise de variância para as características de crescimento e teores de nutrientes na parte aérea das plantas, respectivamente. Os resultados da análise da variância indicaram que as doses de superfosfato simples influenciaram significativamente todas as características de crescimento e teores de nutrientes na parte aérea das plantas. As variáveis de crescimento apresentaram comportamento quadrático em relação às doses de superfosfato simples aplicadas ao substrato. Para os teores

Tabela 1 - Resumo da análise de variância para as variáveis altura de plantas (AP - cm), área foliar (AF - $\mathrm{cm}^{2}$ ), massa seca da parte aérea (MSPA -g) e massa seca do sistema radicular (MSSR - g) de mudas de pinhão manso cultivadas em substrato contendo diferentes doses de fósforo aos 30 dias após a semeadura

\begin{tabular}{cccccc}
\hline \multicolumn{7}{c}{ Quadrado médio } \\
\hline FV & GL & AP & AF & MSPA & MSSR \\
\hline Dose de Fósforo & 5 & $49,97^{*}$ & $10314,93^{*}$ & $0,30^{*}$ & $0,049^{*}$ \\
Resíduo & 30 & 3,65 & 1155,25 & 0,09 & 0,004 \\
\hline CV \% & - & 11,10 & 23,55 & 22,77 & 39,05 \\
\hline Regressão P & - & & & 0,08 & $0,135^{*}$ \\
Efeito Linear & 1 & $105,26^{*}$ & $13821,82^{*}$ & $0,85^{*}$ & $0,081^{*}$ \\
Efeito quadrático & 1 & $94,50^{*}$ & $33856,88^{*}$ & 0,18 & 0,016 \\
Desvio & 3 & 16,70 & 1298,65 & &
\end{tabular}

* significativo a $5 \%$ pelo teste $\mathrm{F}$. ns - não significativo

Tabela 2 - Resumo da análise de variância dos teores de N, P, K, Ca, Mg e S $\left(\mathrm{g} \mathrm{kg}^{-1}\right)$ na parte aérea de mudas de pinhão manso cultivadas em substrato contendo diferentes doses de fósforo aos 30 dias após a semeadura

\begin{tabular}{|c|c|c|c|c|c|c|c|}
\hline \multicolumn{8}{|c|}{ Quadrado médio } \\
\hline FV & GL & $\mathrm{N}$ & $\mathrm{P}$ & $\mathrm{K}$ & $\mathrm{Ca}$ & $\mathrm{Mg}$ & $\mathrm{S}$ \\
\hline Dose de Fósforo & 5 & $94,31 *$ & $31,19^{*}$ & $123,17^{*}$ & $1,12 *$ & $65,83^{*}$ & $13,06^{*}$ \\
\hline Resíduo & 30 & 29,01 & 2,14 & 4,55 & 0,11 & 1,37 & 0,20 \\
\hline $\mathrm{CV} \%$ & - & 13,67 & 16,74 & 14,52 & 11,20 & 7,20 & 9,62 \\
\hline Regressão P & - & & & & & & \\
\hline Efeito Linear & 1 & $305,67^{*}$ & $102,24 *$ & $445,96^{*}$ & $1,41^{*}$ & $149,53 *$ & $19,40 *$ \\
\hline Efeito quadrático & 1 & 25,19 & 8,03 & $46,56^{*}$ & $0,94^{*}$ & $169,71 *$ & $27,02 *$ \\
\hline Desvio & 3 & 46,90 & 15,23 & 41,12 & 1,08 & 3,31 & 6,28 \\
\hline
\end{tabular}

* significativo a 5\% pelo teste F. ns - não significativo 
de macronutrientes na parte aérea das mudas somente os teores de $\mathrm{N}$ e $\mathrm{P}$ apresentaram aumento linear com as doses aplicadas, sendo que os demais nutrientes apresentaram comportamento quadrático.

A altura das plantas de pinhão manso atingiu o valor máximo com a dose de superfosfato estimada em $8,2 \mathrm{~kg} \mathrm{~m}^{-3}$ (FIG. 1A), a área foliar com $7,4 \mathrm{~kg} \mathrm{~m}^{-3}$ (FIG. 1B), a massa seca da parte aérea com $5,7 \mathrm{~kg} \mathrm{~m}^{-3}$ (FIG. 1C) e a massa seca das raízes com $6,1 \mathrm{~kg} \mathrm{~m}^{-3}$ (FIG. 1D). A altura da planta na dose de máximo crescimento aumentou $33 \%$ e a massa seca da parte aérea $27 \%$ quando comparadas ao substrato sem adição de fósforo. No entanto, a área foliar aumentou $136 \%$ e a massa seca das raízes apresentou incremento de $172 \%$ na mesma comparação. Este efeito do fósforo é importante na produção de mudas de boa qualidade porque melhora duas características muito importantes da planta que são a capacidade fotossintética e de absorção de água e nutrientes. Doses de fósforo muito elevadas, por outro lado, provocaram redução no crescimento da planta, principalmente da área foliar e das raízes, o que prejudica a qualidade das mudas.

O crescimento ótimo das mudas de pinhão manso foi obtido com a adição de superfosfato simples na faixa de 5 a $8 \mathrm{~kg} \mathrm{~m}^{-3}$. Outros estudos confirmam o efeito positivo da adição de fósforo sobre o crescimento de mudas de pinhão manso (CARVALHO, 2008) e de diversas outras espécies como tamarindeiro (FERREIRA et al., 2008), goiabeira (LACERDA et al., 2009), gravioleira (SOARES; LIMA; CRISÓSTOMO, 2007; SOUZA et al., 2003) e maracujazeiro (DAVID et al., 2008; PRADO; VALE; ROMUALDO, 2005). A dose que promove o maior crescimento das plantas, no entanto, varia numa faixa muito ampla, pois este valor depende tanto de características específicas da espécie, quanto do substrato utilizado, cujos atributos químicos e físicos podem influenciar o comportamento do fósforo e sua absorção pelas raízes das plantas.
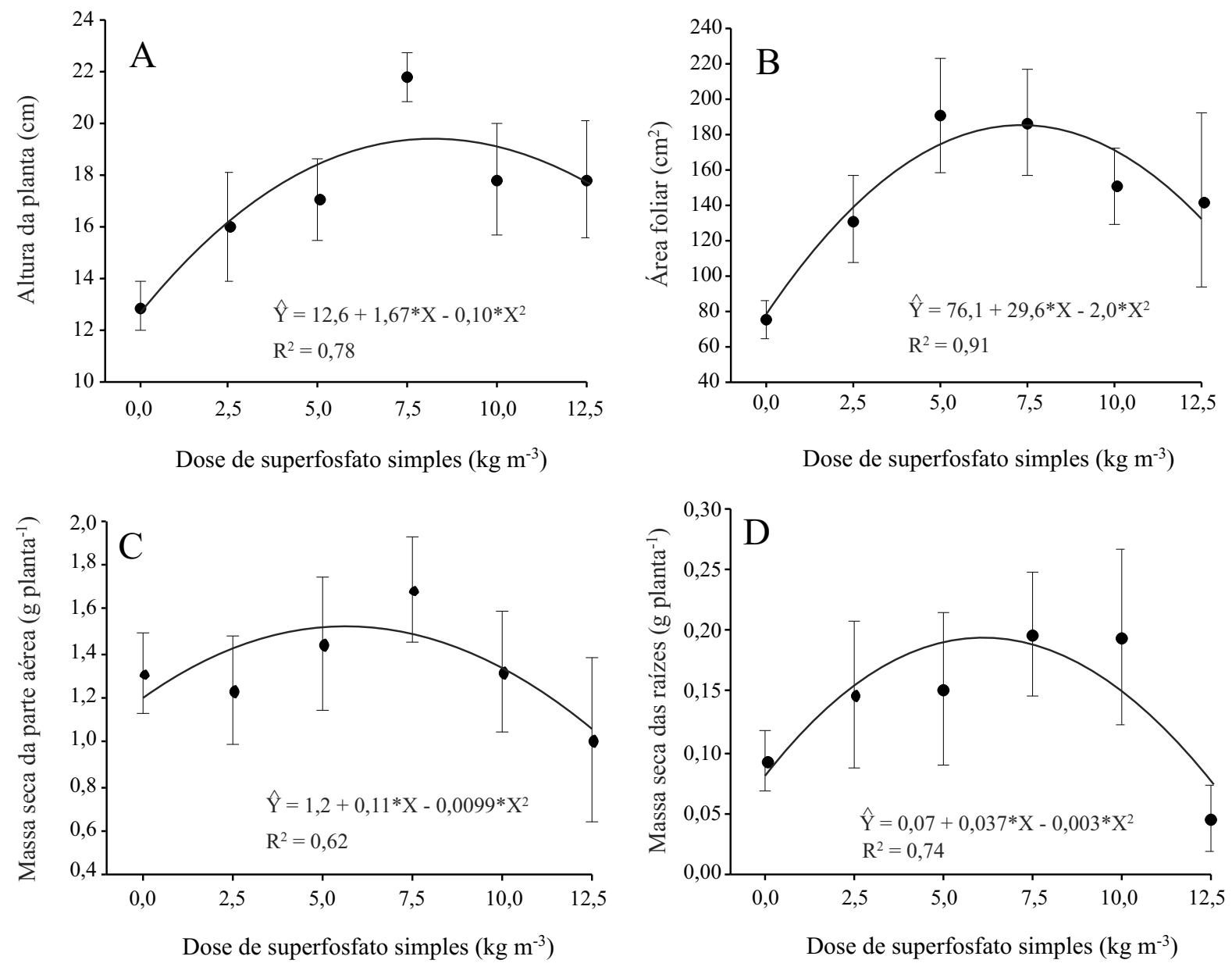

Figura 1 - Efeito de doses de superfosfato simples sobre a altura das plantas (A), área foliar (B), massa seca da parte aérea (C) e de raízes (D) de mudas de pinhão manso. Barras verticais indicam o desvio padrão da média 
Os teores de $\mathrm{N}$ e $\mathrm{P}$ no tecido vegetal aumentaram linearmente em resposta às doses de superfosfato simples aplicadas ao substrato (FIG. 2A; FIG. B). O aumento do fósforo é conseqüência direta da maior disponibilidade deste nutriente no substrato, mas o nitrogênio provavelmente aumentou devido à maior
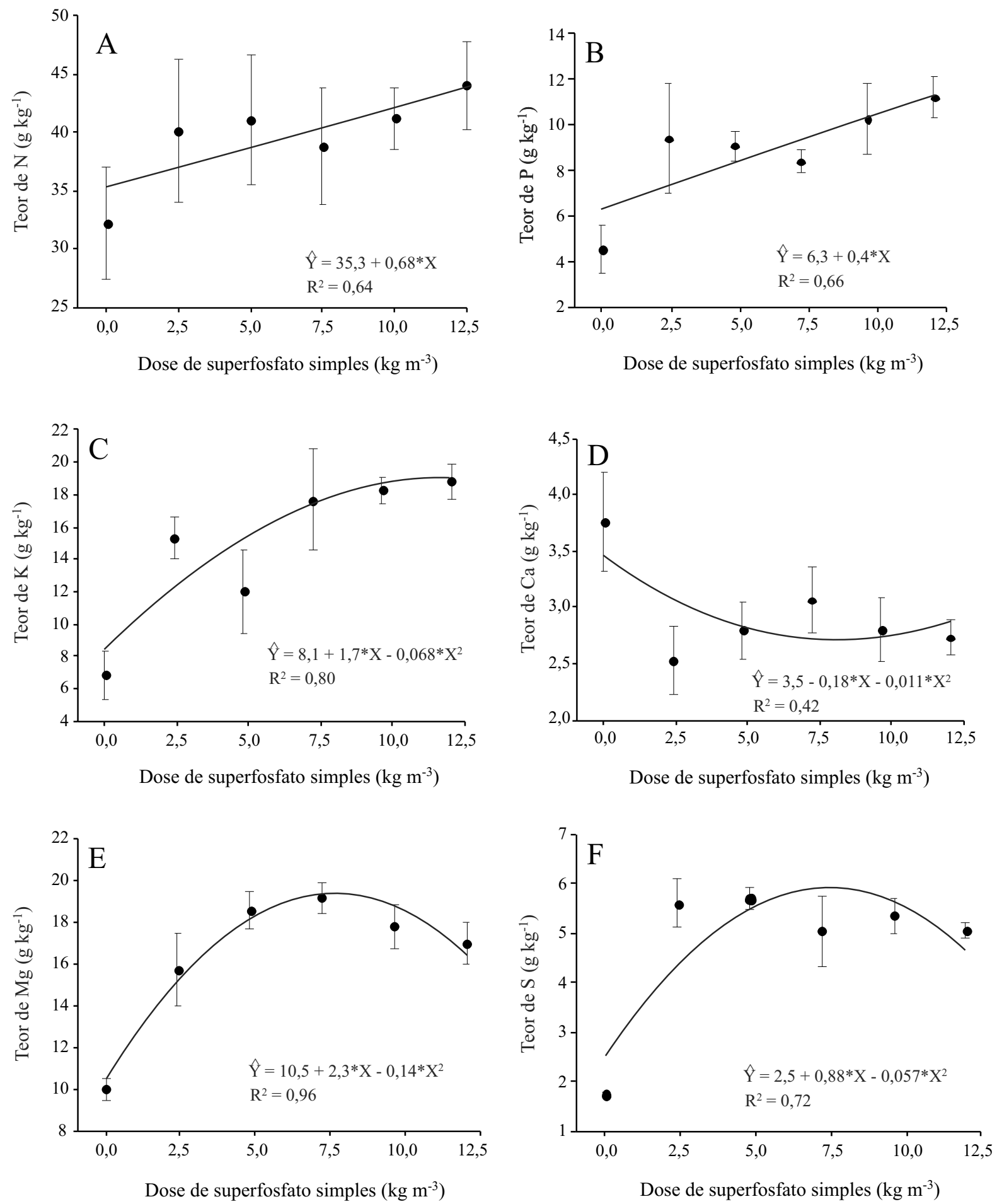

Figura 2 - Efeito de doses de superfosfato simples sobre os teores de nitrogênio (A), fósforo (B), potássio (C), cálcio (D), magnésio (E) e enxofre $(F)$ na parte aérea de plântulas de pinhão manso. Barras verticais indicam o desvio padrão da média 
quantidade de raízes e pela importância do $\mathrm{P}$ para a fisiologia da planta, principalmente em processos demandantes de energia como a absorção e assimilação do nitrogênio. Os teores de $\mathrm{N}$ e $\mathrm{P}$ aumentaram inclusive nas doses em que houve redução no crescimento de raízes e área foliar, o que caracteriza um consumo de luxo que não se reverte em crescimento. Em geral, as culturas perenes necessitam de grandes teores de $\mathrm{P}$ no substrato na fase de plântulas, diminuindo essa exigência com a idade (NOVAIS; SMITY, 1999), o que reforça a importância da adição de fósforo ao substrato para produção de mudas de pinhão manso.

O teor de potássio aumentou consideravelmente com a adição das doses mais baixas do fertilizante fosfatado (FIG. 2C), mas doses maiores tiveram menor efeito no aumento do teor de potássio na parte aérea das plantas. A adição de $2,5 \mathrm{~kg} \mathrm{~m}^{-3}$ de superfosfato simples ao substrato propiciou aumento de $47 \%$ no teor de potássio no tecido vegetal; mas o incremento seguinte do adubo fosfatado (de 2,5 para $5 \mathrm{~kg} \mathrm{~m}^{-3}$ ) propiciou aumento de somente $25 \%$ e nas maiores doses testadas o efeito foi ainda menos expressivo.

Embora o superfosfato simples possua cerca de $25 \%$ de cálcio em sua composição, a adição deste fertilizante provocou redução no teor deste nutriente no tecido da planta (FIG. 2D). Esta redução foi mais intensa no tratamento em que o substrato possuía fertilização fosfatada em relação àquele que não recebeu adubação, mas as doses mais elevadas não provocaram redução contínua nos teores deste nutriente. Por exemplo, entre as doses de 5,0 e $12,5 \mathrm{~kg} \mathrm{~m}^{-3}$ o teor de cálcio é praticamente o mesmo.

Os teores de magnésio e enxofre apresentaram aumento expressivo com a adição de fertilizante fosfatado ao substrato (FIG. 2E; FIG. 2F). Os teores máximos foram observados próximos à dose estimada de $8 \mathrm{~kg} \mathrm{~m}^{-3}$. O enxofre também é um nutriente presente na composição do superfosfato simples.

\section{Conclusões}

1. O crescimento máximo das plantas de pinhão manso foi observado com a adição de superfosfato simples ao substrato em doses estimadas na faixa de 5 a $8 \mathrm{~kg} \mathrm{~m}^{-3}$. O fertilizante fosfatado favoreceu o crescimento principalmente de raízes e área foliar;

2. A adição do adubo fosfatado propiciou aumento no tecido vegetal do teor de todos os macronutrientes, exceto o cálcio.

\section{Agradecimentos}

À Fundação de Apoio à Pesquisa do Estado da Paraíba (FAPESQ/PB) e Conselho Nacional de Desenvolvimento Científico e Tecnológico (CNPq) pelo apoio financeiro. Bolsa DCR ao primeiro autor.

\section{Referências}

ABREU, N. A. A. et al. Crescimento de mudas de pitangueira (Eugenia uniflora L.) em substratos com utilização de superfosfato simples. Ciência e Agrotecnologia, v. 29, n. 06, p. 1117-1124, 2005.

ADAMI, C.; HEBLING, S. Efeitos de diferentes fontes de fosfato no crescimento inicial de Schizolobium parahyba (Vell.) S.F. Blake. Natureza on line, v. 03, n. 01, p. 13-18, 2005.

CARMELLO, Q. A. C. Nutrição e adubação de mudas hortícolas. In: MINAMI, Q. (Ed.). Produção de mudas de alta qualidade em horticultura. São Paulo: T. A. Queiroz, 1995. p. 7-27.

CARVALHO, A. M. X. Fungos micorrízicos arbusculares no crescimento de mudas de pinhão manso (Jatropha curcas $\mathbf{L}$.). 2008. 48 f. Dissertação (Mestrado em Microbiologia Agrícola) - Universidade Fedeal de Viçosa, Viçosa, 2008.

CRUSCIOL, C. A. C. et al. Doses de fósforo e crescimento radicular de cultivares de arroz de terras altas. Bragantia, v. 64, n. 04, p. 643-649, 2005.

DAVID, M. A. et al. Efeito de doses de superfosfato simples e de matéria orgânica sobre o crescimento de mudas de maracujazeiro amarelo. Pesquisa Agropecuária Tropical, v. 38, n. 03, p. 147-152, 2008.

FERREIRA, E. A. et al. Adubação fosfatada e potássica na formação de mudas de tamarindeiro. Scientia Agrária, v. 09, n. 04, p. 475-480, 2008.

GARCIA, G. O. et al. Análise nuticional de mudas de eucalipto submetidas à aplicação de lodo de esgoto doméstico. Engenharia Ambiental, v. 06, n. 03, p. 275-290, 2009.

LACERDA, J. S. et al. Crescimento de mudas de goiabeira 'Paluma' em substratos fertilizados com fósforo. Engenharia Ambiental, v.06, n. 02, p. 650-662, 2009.

LE POIDEVIN, N.; ROBINSON, L. A. Métodos de diagnósticos foliares utilizados nas plantações do grupo Booken na Guiana inglesa: amostragem e técnica de análises. Fertilité, v. 21, p. 03-11, 1964.

LEÃO, D. A. S. Estresse hídrico e adubação fosfatada no desenvolvimento inicial e na qualidade da forragem da gliricídia (Gliricídia sepium (Jacq.) Steud. e do sorgo (Sorghum bicolor (L.) Moench.). 2006. 56 f. Dissertação (Mestrado em Zootecnia) - Universidade Fedeal de Campina Grande, Patos, 2006.

MENDONÇA, V. et al. Crescimento de mudas de mamoeiro Formosa em substratos com utilização de composto orgânico e 
superfosfato simples. Ciência e Agrotecnologia, v. 30, n. 05, p. 861-868, 2006.

NOVAIS, R. F.; SMYTH, T. J. Fósforo em solos e planta em condições tropicais. Viçosa, MG: UFV, 1999. 399 p.

POZZA, A. A. A. et al. Suprimento de fósforo na produção e intensidade da cercosporiose de mudas de cafeeiro em tubetes. Ciência e Agrotecnologia, v. 26, n. 05, p. 970-976, 2002.

PRADO, R. M.; VALE, D. W.; ROMUALDO, L. M. Fósforo na nutrição e produção de mudas de maracujazeiro. Acta Scientarum. Agronomy, v. 27, n. 03, p. 493-498, 2005.

SANT'ANA, E. P. et al. Utilização de fósforo e características do sistema radicular e da parte aérea de plantas de arroz. Ciência e Agrotecnologia, v. 27, n. 02, p. 370-381, 2003.

SANTOS, M. G. et al. Gás exchange and yield response to foliar phosphorus application in Phaseolus vulgaris L. under drought. Brazilian Jounal of Physiology, v. 16, n. 03, p. 171-179, 2004.

SEVERINO, L. S.; LIMA, R. L. S.; BELTRÃO, N. E. M. Composição química de onze materiais orgânicos utilizados em substratos para produção de mudas. Campina Grande: EMBRAPA Algodão, 2006. (Comunicado Técnico, 278).

SEVERINO, L. S.; VALE, L. S.; BELTRÃO, N. E. M. A Simple method for measurement of Jatropha curcas leaf area. Revista Brasileira de Oleaginosas e Fibrosas, v. 11, n. 01, p. 09-14, 2007.

SILVA, A. A.; DELATORRE, C. A. Alterações na arquitetura de raiz em resposta à disponibilidade de fósforo e nitrogênio. Revista de Ciência Agroveterinárias, v. 08, n. 02, p.152-163, 2009.

SOARES, I.; LIMA, S. C.; CRISÓSTOMO, L. A. Crescimento e composição mineral de mudas de gravioleira em resposta a doses de fósforo. Revista Ciência Agronômica, v. 38, n. 04, p. 343-349, 2007.

SOUZA, C. A. S. et al. Crescimento de mudas de gravioleira (Anonna muricata L.) em substrato com superfosfato simples e vermicomposto. Revista Brasileira de Fruticultura, v. 25, n. 03, p.453-456, 2003.

SOUZA, H. A. et al. Adubação nitrogenada e fosfatada no desenvolvimento de mudas de uvaia. Bioscience Journal, v. 25, n. 01, p. 99-103, 2009.

VICHIATO, M. Influência da fertilização do porta-enxerto tangerineira (Citrus reshni Hort. Ex Tan. cv. Cleópatra) em tubetes, até a repicagem. 1996. 82 p. Dissertação (Mestrado em Fitotecnia) - Universidade Federal de Lavras, Lavras, 1996.

YAMADA, T. Nutrição fosfatada melhora a resistência da planta às doenças. Informações Agronômicas, n. 97, p. 1-2, 2002. 